\title{
Understanding Learning and the Components of the Learning Process in Medical Education: A Review of the Literature
}

\author{
Verona Sukrajh, and Adegoke O. Adefolalu
}

\section{ABSTRACT}

\begin{abstract}
Active learning can be described as any evidence-based strategy that seeks to engage the students during their learning process by deliberately involving them in participating in some form of meaningful activities, upon which they are subsequently tasked to think about what they have just done. It is learner-centred in its approach, thereby fostering deeper learning on the part of the student. The understanding of how people learn has developed substantially over the decades with different theories and approaches to learning haven been described by various authors in the literature. The importance of this is that all these postulated theories have offered greater insight into the learning process in particular. The current paper aims to describe the learning process and its components with a view towards providing a better understanding of the learning process, exploring some of the theoretical background that underpinned the learning and the learning process.
\end{abstract}

Keywords: medical education, learning process, metacognition, active learning

\section{INTRODUCTION}

Active learning encourages metacognition, a process that engage the students in higher order of thinking in their analysis, synthesis and evaluation of taught contents [1]. According to the medical literature, it is widely believed that students should not be left to merely sit and listen passively as onlookers during the teaching and learning periods, instead they should be tasked to internalize what they have learnt or what they have been taught through a process of continuous discussion and application of the taught contents [2]. Although there is no precise definition of active learning, however the characteristics of active learning have been outlined as having the three interrelated components listed below. The first component is Intentional engagement, which purport that the student learns through performing a skill/s either in real or simulated settings. This is followed by Purposeful observation, here the student learns through watching and listening through role play or role modelling either in a real or simulated setting. The third element of active learning is called Critical reflection, this third component is essential in active learning as it serves to concretize the learning that has taken place by giving meaning to it through analyzing and questioning what the students are expected to have learned, thereby enabling the reframing of the learners' experience [3]. Globally, education experts have widely accepted the key elements of the learning process, namely, the cognitive, affective and metacognitive components that direct optimal student learning [4-5]. To have a comprehensive understanding of the learning process,
Published Online: February 20, 2021

ISSN: $2736-4534$

DOI : $10.24018 /$ ejedu.2021.2.1.53

\section{Dr V. Sukrajh}

Practice of Medicine (POME) Unit, School of Medicine, Sefako Makgatho Health Sciences University, South Africa.

e-mail: verona.sukrajh@smu.ac.za

\section{Dr AO Adefolalu*}

Practice of Medicine (POME) Unit, School of Medicine, Sefako Makgatho Health Sciences University, South Africa e-mail: adegoke.adefolalu ${ }^{@}$ smu.ac.za

*Corresponding Author

it is necessary to explored the theoretical underpinnings of these components, starting with the cognitive component of the learning process and then to the social and behavioural aspects of learning as they entwined within peer teaching, one of the strategies used by medical educators to enhance active learning among their students.

\section{COGNITIVISM AND ThE SOCIAL IMPACT OF LEARNING}

Cognitivism is the focus on the inner mental activities of the human mind and is imperative for understanding how learning occurs. It is the mental process of processing information by relating, structuring, analyzing, concretizing, applying, memorizing, critical processing and selecting of major and minor points [4]. This component of learning fosters a key learning theory crucial in medical education where the cognitivist orientation is aimed at meaningful learning through relating new knowledge to that which is already known [6]. The leading psychologist Vygotsky presented a theory on cognitive development with a focus on the role of cultural and social interactions. A key feature of this theory is the Zone of Proximal Development (ZPD) that is based on two levels of attainment. One level is the actual development level, which is a child's capability of problem solving without the guidance from adults or collaboration with capable peers. The second is the level of potential development, which is a child's capability of problem solving with the guidance from adults or collaboration with capable peers. The ZPD is the distance between the actual developmental level and the level of potential development.

Therefore, the presence of a more knowledgeable person 
can assist a child in potentially developing and acquiring more knowledge, but such knowledge must be at the child's level of comprehension [7]. In other words, the teacher must be capable of matching the instructional strategies so that it is attuned to the students learning capabilities. This Vygotskian school of thought was employed in peer teaching to support the cognitive benefits of learning, which suggests that peers may perceive the ZPD more easily than an expert [8-10].

Social interaction plays an important role in learning and is a crucial feature that is embedded in cognitivism. According to the social cognitive theory, learning occurs within a social environment and can occur by mere observation alone. This theory suggests that learning occurs through the interactions with, and the observations of others, through which students are able to acquire knowledge, skills, strategies, beliefs and attitudes [11]. To assimilate new knowledge or skills students, often imitate and reinforce the observed behaviour by rehearsing it [6]. Another form of learning, where features of social-cognitive and behavioural components are interlinked is referred to as cooperative learning, which is defined as a carefully structured form of group work where students pursue common goals while being assessed individually. At a fundamental level, cooperative learning is based on cooperation rather than competition to promote learning.

The foundation of cooperative learning is built on the social interdependence, cognitive development and behavioural learning theories [12]. Social interdependence arises when the outcome of the individuals is influenced by their own and the other's actions. The components that constitute the social interdependence theory reveal some of the key elements which enhance interaction and promote learning, these are: social interdependence, entitativity, promotive interaction, individual accountability and personal responsibility, and social skills [13]. Social interdependence can be positive, negative or be non-existent. Positive interdependence is where students work within a group seeking a common goal and care about one another's learning [14]. This cooperation leans towards promoting interactions as students encourage and facilitate one another's endeavor to learn. Positive interdependence could encourage the development of material interdependence where the learning material which is interrelated is divided within a group so that each member's contribution is required to solve the problem [15]. This thus places some kind of responsibility on every member of the group to strive towards in giving their best effort as any resultant outcome would reflect the entire group's performance [13].

In addition, positive interdependence may be improved further by encouraging the students within a group to provide feedback to their peers first before the group's combined feedback, this might lead to significant improvement of the individual student's performance and could subsequently assist the group in achieving its outcome [15].

Entitativity is the perception that the group is a unified whole with each member coalescing in pursuit of the same goal. The identity of an individual member is defined by that of the group which leads to members making greater effort for the benefit of the group [13]. Promotive interaction is the facilitation shared within group members to support and encourage one another through the process of accomplishing the common goal. This could be in the form of feedback to improve performance or sharing of resources. Individual accountability and personal responsibility are fundamental to the cooperative learning process. If the members of the group feel that they are answerable and dependent on one another to reach their common goal, then the degree of responsibility towards the group is greater, which usually results in increased accountability [13], [15], [16].

Social skill is another key component of the social interdependence theory as it guides the development towards a better relationship between group members. These include the ability to support and trust each other, ability to communicate through sharing of information and ideas, and perhaps in the event of any conflict that could arise, being able to come to a constructive settlement. These have been shown to foster good relationships among members, which often results in more positive achievements [13]. Another feature of cooperative learning is cognitive development, which once again focuses on the theories of Vygotsky and Piaget. These theories view working cooperatively with more capable peers or facilitators as an essential prerequisite for an individual's cognitive development and intellectual growth. Learning through cooperation assists students in cognitive rehearsing and restructuring of information, enabling them to incorporate such learnt information into their existing knowledge, which enhances the retention of such knowledge [12].

\section{AfFective COMPONENT Of THE LEARNING PROCESS}

Motivation plays an important role in learning, within the affective component of learning are the feelings and emotions that affect the progression of learning. The affective component of learning explores the motivation that make students want to learn. Behavioural learning theory in cooperative learning is driven by extrinsic motivation that provides incentives for members of a group to participate in the group's effort as opposed to the social interdependence theory, which is based on intrinsic motivation that is driven by interpersonal factors and a group effort to achieve a common goal [12]. Self Determination Theory (SDT) is a key theory that explores the psychology of the motivational process. This theory differentiates several distinct types of motivation with the most basic distinction focusing on the difference between intrinsic and extrinsic motivation to demonstrate the rationale in achieving different goals [1718]. According to some researchers, understanding the SDT may uncover numerous elements that determine the failures and successes in medical education [19]. Intrinsic motivation is driven by an inherent interest in the activity and a natural inclination towards assimilation, mastery and exploration that is vital for cognitive and social development. When the students experience a sense of autonomy or free choice to continue the activity, they then spend more time on the activity which increases their intrinsic motivation which leads to improved academic performance and well-being [17], [19].

Furthermore, research has shown that learning for teaching created more intrinsic motivation than learning for writing an assessment. However, there are several factors that hinder intrinsic motivation in individuals such as deadlines, directives, evaluations and imposed goals. Extrinsic motivation in contrast pertains to pursing an activity to attain 
a separable outcome of instrumental value. Even though extrinsic motivators often hinder intrinsic motivation due to the lack of autonomy, students can still feel autonomous while extrinsically motivated [18]. According to the SDT, this is due to the differing degrees to which the value and regulation of the requested behaviour have been internalized and integrated [17]. Internalization is the process of realizing a value and integration is the process of transformation of a value into their own to emanate from within their sense of self. Within the SDT, there is a sub theory known as Organismic Integration Theory (OIT), which details the different forms of extrinsic motivation and the contextual factors that influence the regulation for these behaviours. The diagrammatic representation of this is illustrated in Figure 1 below which depicted the self-determination continuum of the various types of motivation. Beginning from the far left is amotivation which is a state of lacking the intent to act. This is followed by the category with the least autonomous forms of extrinsic motivation: external regulation, which is behaviour performed to complete an external demand. Introjected regulation that appears next is a type of internal regulation where behaviour is regulated by contingent selfesteem such as ego involvement. Moving on, as a more autonomous form of extrinsic motivation, is regulation of behaviour through identification, which involves a conscious valuing of a regulation. The most autonomous form of extrinsic motivation is the integrated regulation. Integration occurs when identified regulations are completely assimilated to the self. This means that they have been evaluated and brought into congruence with one's others values and needs [17].

\section{METACOGNITIVE COMPONENT OF THE LEARNING PROCESS}

The cognitive and affective components of learning may not be sufficient for the learning process if the student does not know how to learn [5]. Metacognition is the insight of one's own mental processing which includes the student's ability to plan study activities, to monitor and evaluate their progress and to identify and attend to any personal lack of or deficient in knowledge [5], [20]. Metacognition can be categorized into two types, namely metacognitive knowledge and metacognitive regulation. Metacognitive knowledge is the knowledge about the strategies one develops in how to acquire knowledge and skills [21]. The development of the student's ability to assess their learning and plan for further knowledge through continuing education includes time management, exploring strategies to keep up to date with journals and explore opportunities to apply new knowledge and gain new experiences and these are considered mature, internalized metacognitive skills [5]. To enhance metacognition the use of active teaching and learning strategies need to be incorporated into the curriculum [22]. Metacognitive regulation is the monitoring of one's level of knowledge, which assists in discovering any deficiencies and employing different strategies to overcome these deficiencies [21]. Some authors have suggested the need for individuals to regularly monitor their metacognition to determine its accuracy for it to be effective in regulating their learning [23]. One of the factors enhancing the accuracy of metacognition is an active approach to learning as opposed to a passive approach [24].

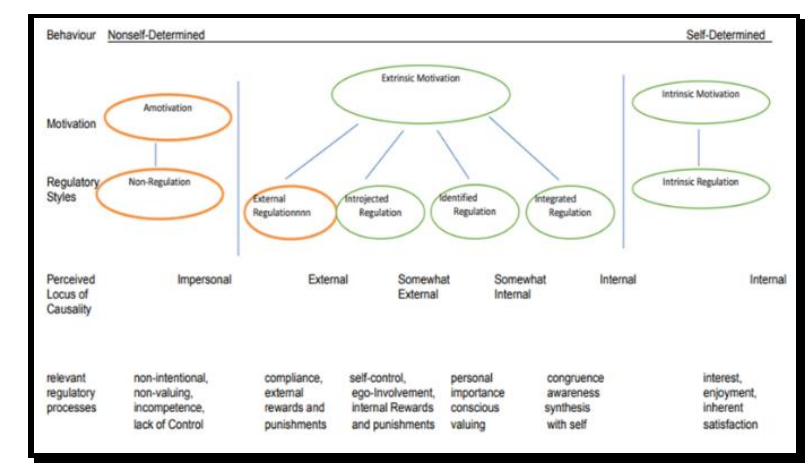

Fig. 1. Self-determination theory illustrating the spectrum of motivation. [Adapted from Ryan \& Deci, 2000]

Therefore, the importance of developing metacognitive skills is crucial for medical doctors as they are increasingly challenged in keeping up with the rapid evolution and expansion of medical knowledge that made the constant changes in professional practice inevitable. This therefore demands that medical educators should prepare their students to embark on life-long learning by mastering their metacognitive skills [25]. Although it is important to emphasize that this is but one of the many skills essential in preparing students to become doctors.

\section{CONCLUSION}

In ensuring active learning among students, it is very vital to adopt the correct strategy that will assist the students to take full responsibility for their learning. This review article has focused on some theories and philosophies around the learning process, at the same time emphasizing the need for better understanding of the learning process, so that medical educators contemplating on choosing one out of the wide variety of teaching and learning methods available in the medical education literature, make an informed decision. Although there is increased interest among medical educators to adopt educational strategy that has been shown to be efficient over the years in enhancing active students learning, more research is still needed in this area.

\section{REFERENCES}

[1] CC. Bonwell, and JA. Elison. Active learning: creating excitement in the classroom. George Washington University. Ashe-Eric Higher Education Report 1, Washington DC, 1991.

[2] AW. Chickering, and ZF. Gamson. Seven principles for good practice. American Association for Higher Education (AAHE) Bulletin, vol. 39, pp. 3-7. 1987.

[3] B. Graffam. Active learning in medical education: Strategies for beginning implementation. Medical Teacher, vol. 29, pp. 38-42, 2007.

[4] JD. Vermunt. Metacognitive and affective aspects of learning styles and strategies: A phenomenographic analysis. Higher Education, vol. 31, pp. 25-50, 1996.

[5] O. Ten Cate, L. Snell, K. Mann, and J. Vermunt. 2004. Orientating teaching towards the learning process. Academic Medicine, vol. 79, no. 3, pp. 209-228, 2004.

[6] DM. Torre, BJ. Daley, JL. Sebastian, and DM Elnicki. Overview of current learning theories for medical educators. The American Journal of Medicine, vol. 119, no. 10, pp. 903-907, 2006.

[7] L. Vygotsky. Interaction between learning and development. Cambridge: Harvard University Press. 1978.

[8] KJ. Topping. Trends in peer learning. Educational Psychology, vol. 25, no. 6, pp. 631-645, 2005. 
[9] O. Ten Cate, and S. Durning. Dimensions and psychology of peer teaching in medical education. Medical Teacher, vol. 29, no. 6, pp. 546552, 2007.

[10] DCM. Taylor, and H. Hamdy. Adult learning theories: Implications for learning and teaching in medical education: AMEE Guide No 83. Medical Teacher, vol. 35, pp. e156-e1572, 2013.

[11] DH. Schunk. Learning theories: an educational perspective. (6th ed). Boston: Pearson. 2012.

[12] DW. Johnson. RJ. Johnson, and KA Smith. Cooperative learning returns to college: what evidence is there that it works? Change, vol. 30, pp. 27-35, 1988.

[13] DW. Johnson and RJ. Johnson. An educational psychology success story: social interdependence theory and cooperative learning. Educational Researcher, vol. 38, no. 5, pp. 365- 379, 2009.

[14] KJ. Topping, \& S. Ehly. 2001. Peer assisted learning: a framework for consultation. Journal of Educational and Psychological Consultation, vol. 12, no 2, pp. 113-132, 2001.

[15] D.M. Torre, C. van der Vleuten, and D. Dolmans. Theoretical perspectives and applications of group learning in Problem-based learning. Medical Teacher, vol 38. pp. 189-195, 2016.

[16] DW. Johnson. \& RJ. Johnson. New developments in social interdependence theory. Genetic. Social and General Psychology, vol. 131, no 4, pp. 285-358, 2005.

[17] RM. Ryan, and EL. Deci. Self-determination theory and the facilitation of intrinsic motivation, social development, and well-being. American Psychology Association, vol. 55, no. 1, pp. 68-78, 2000.

[18] RM. Ryan \& ELL. Deci, E.L. Facilitating optimal motivation and psychological well-being across life's domains. Canadian Psychology, vol. 49, no. 1, pp. 14-34, 2008.

[19] O. Ten Cate, A. Rashmi, GC. Willams, and K. Willams, How selfdetermination theory can assist our understanding of teaching and learning processes in medical education. AMEE Guide No 59. Medical Teacher, vol. 33, pp. 961-973, 2011.

[20] MVJ. Veerman, HAM. van Hout-Wolters, and P. Afflerbach, Metacognition and learning: conceptual and methodological considerations. Metacognition Learning, vol. 1, pp. 3-14, 2006.

[21] E. Driessen. When I say... metacognition. Medical Education, vol. 48, pp. 561-562, 2014.

[22] EA. Van Vliet, JC. Winnips, \& N. Brouwer. Flipped class pedagogy enhances student metacognition and collaboration learning strategies in higher education but effects does not persist. CBE Life Sciences Education, vol. 14, pp. 1-10, 2015.

[23] J. Metcalfe, Metacognitive judgements and control of study. Current Directions in Psychological Science, vol. 18, no. 3, pp. 159-163, 2009.

[24] KW. Thiede, \& DJ. Therriault. Accuracy of metacognitive monitoring affects learning of texts. Journal of Educational Psychology, vol. 95, no. 1, pp. 66-73, 2003.

[25] NJ. Burman, CK. Boscardin, and SM. van Schaik, S.M. Career long learning: relationship between cognitive and metacognitive skills. Medical Teacher, vol. 36, pp. 715-723, 2014.

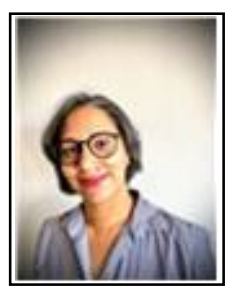

Dr Verona Sukrajh, is a certified medical educator and has been involved in undergraduate medical education for over 10 years, especially in the aspect of teaching and learning, skills development, and curriculum development. She is currently a senior faculty at the School of Medicine, Sefako Makgatho Health Sciences University in South Africa, where she teaches HIV/AIDS Epidemiology, Communication skills and other competencies required of a medical graduate. She holds BSc (Hons), MBCHB degree, Diploma in HIV Management (SA), and MPhil (Health Professions Education) from Stellenbosch University. Dr Sukrajh interests include Innovative Teaching techniques, Curriculum development, Assessment modalities, and Peer-teaching in medical education. She is a member of the university's Curriculum Development Committee (CDC), and the Academic Planning \& Curriculum Review Committee (APCDC). Furthermore, she is a general practitioner focusing on preventative health care and health education.

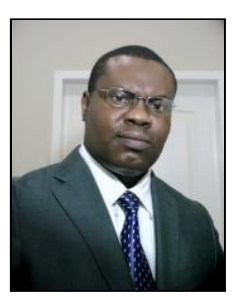

Dr Adegoke O. Adefolalu, (MBCHB, DipHIV Man (SA), MPH, PhD, FRSPH) is a faculty currently with the School of Medicine at the Sefako Makgatho Health Sciences University, South Africa, where he teaches Epidemiology and Research Methods within the Practice of Medicine integrated curriculum of the MBCHB programme. A Public health physician with special interest in medical education, some of his research interests include clinical epidemiology, HIV/AIDS, health systems, health behaviour and health determinants. An established researcher, Dr Adefolalu has published extensively in peer-reviewed journals, functioned as associate editor for multiple scientific journals, and has been serving as reviewer for many scientific journals for over 10 years. He is a fellow of the Royal Society of Public Health (UK), and a member of the Royal Society of Tropical Medicine and Hygiene. An astute health advocate, he mentors both staff and students, and he is actively involved in faculty development. 